\title{
O Adicional de Insalubridade: Monetização da Saúde Como Dificuldade à Concepção de Sociedade Fraterna
}

\author{
El Adicional de Insalubridad: Monetización de la Salud como Dificultad a \\ la Concepción de Sociedad Fraterna \\ The Additional of Insalubrity: Monetization of Health as Difficulty to the \\ Conception of Fraternal Society
}

Luigi dos Santos Gomes ${ }^{1}$

Alexander Santos Kubiak ${ }^{2}$

Deisemara Turatti Langoski ${ }^{3}$

\begin{abstract}
Resumo
No preâmbulo da Constituição Federal de 1988, destaca-se o desejo de se criar uma sociedade igualitária e fraterna. Entretanto, o direito ao adicional de insalubridade distorce essa ótica, uma vez que o benefício admite a monetização da saúde do trabalhador ao promover que a relação naturalmente desigual entre empregado e empregador, se torne ainda mais distante. $\mathrm{O}$ presente trabalho tem o objetivo de analisar o adicional de insalubridade, sua incompatibilidade com o conceito de fraternidade e apresentar alternativas para melhorar a saúde dos trabalhadores. Se utilizou o método dedutivo embasado em pesquisa bibliográfica. O adicional de insalubridade resulta em um direito desumano, pois o empregador transforma o desgaste da saúde do empregado em lucro, o que é constitucionalmente aceito. Ademais, não existem políticas públicas efetivas que garantam a extinção dos riscos no ambiente de trabalho, mas o apoio financeiro como recompensa ao trabalhador que expõe sua saúde, o que remedia, mas não previne o problema. Embora haja trabalhos que não tem como extinguir as insalubridades, sendo nesses casos admissível o adicional, devem existir políticas públicas que eliminem os riscos à saúde do trabalhador, caso contrário, a monetização continuará sendo uma triste realidade no Brasil, a qual não condiz com uma sociedade fraterna, um dos objetivos do Estado Democrático de Direito.
\end{abstract}

Palavras-Chave: Adicional de Insalubridade; Fraternidade; Trabalho; Constituição Federal; Saúde.

\section{Resumen}

En el preámbulo de la Constitución Federal de 1988, se destaca el deseo de crear una sociedad igualitaria y fraterna. Sin embargo, el derecho al adicional de insalubridad distorsiona esa óptica, ya que el beneficio admite la monetización de la salud del trabajador al promover que la relación naturalmente desigual entre empleado y empleador, se vuelva aún más lejos. El presente trabajo tiene el objetivo de analizar el adicional de insalubridad, su incompatibilidad con el concepto de fraternidad y presentar alternativas para mejorar la salud de los trabajadores. Se utilizó el método deductivo basado en la investigación bibliográfica. El adicional de insalubridad resulta en un derecho inhumano, pues el empleador transforma el desgaste de la salud del empleado en lucro, lo que es constitucionalmente aceptado. Además, no existen políticas públicas efectivas que garanticen la extinción de los riesgos en el ambiente de trabajo, sino el apoyo financiero como recompensa al trabajador que expone su salud, lo que remedia, pero no previene el problema. Aunque hay trabajos que no tienen como extinguir las insalubridades, siendo en esos casos admisible el adicional, deben existir políticas públicas que

\footnotetext{
${ }^{1}$ Graduando em Direito; Universidade Federal do Pampa - Unipampa; Santana do Livramento, Rio Grande do Sul, Brasil; dosgomes98@ hotmail.com

${ }^{2}$ Graduando em Direito; Universidade Federal do Pampa - Unipampa; Santana do Livramento, Rio Grande do Sul, Brasil; Solid.Alex@yahoo.com.br

${ }^{3}$ Doutora em Direito UFSC; Universidade Federal do Pampa - Unipampa; Santana do Livramento, Rio Grande do Sul, Brasil; deisemaraturatti@unipampa.edu.br
} 
eliminen los riesgos a la salud del trabajador, de lo contrario, la monetización continuará siendo una triste realidad en Brasil, la cual no condice con una. sociedad fraterna, uno de los objetivos del Estado Democrático de Derecho.

Palabras claves: Adicional de Insalubridad; Fraternidad; Trabajo; Constitución Federal; Salud.

\begin{abstract}
In the preamble of the Federal Constitution of 1988, the desire to create an egalitarian and fraternal society is highlighted. However, the additional of insalubrity distorts this view, since the benefit admits monetization of worker health by promoting that the naturally unequal relationship between employee and employer becomes even more distant. The present work has the objective of analyzing the additional of insalubrity, its incompatibility with the concept of fraternity and presenting alternatives to improve workers' health. The deductive method based on bibliographic research was used. The additional of insalubrity results in an heartless right, because the employer turns the harm of employee health into profit, which is constitutionally accepted. In addition, there are no effective public policies that guarantee the extinction of risks in the work environment, but the financial support as a reward to the worker who exposes his health, which remedies, but does not prevent the problem. Although there are works that can not extinguish the insalubrity, and in these cases the additional is admissible, there must be public policies that eliminate the risks to the health of the worker, otherwise monetization will continue to be a sad reality in Brazil, which is not compatible with a fraternal society, one of the objectives of the Democratic State of Law.
\end{abstract}

Keywords: Additional of Insalubrity; Fraternity; Work; Federal Constitution; Health.

\title{
1. Introdução
}

O presente artigo tem como finalidade discutir a incompatibilidade do direito ao adicional de insalubridade com a intenção presente na Constituição Federal de criar-se uma sociedade mais fraterna e justa. Embora em primeiro momento o adicional pareça ser um direito protetivo aos trabalhadores e justo, ao se analisar de forma mais crítica o adicional é possível perceber que na realidade o que acontece muitas vezes é uma compra da saúde dos empregados por parte do patrão.

A ideia do princípio da fraternidade como um valor jurídico ainda é nova e não conhecida por todos, porém vem se consolidando nos últimos anos, tendo até mesmo sido citada em decisões de ministros do Supremo Tribunal Federal e tendo ocorrido congressos especificamente sobre o tema.

Ao longo do artigo irá ser analisada a atual legislação que trata sobre o adicional de insalubridade, verificando como a Constituição, a Consolidação das Leis do Trabalho e outras normas tratam o tema. Além disso, serão citadas opiniões da doutrina sobre o tema, assim como da jurisprudência atual.

Após o exame do adicional, será estudada a ideia de fraternidade no direito, mostrando a opinião de juristas e decisões onde a fraternidade foi usada como um princípio jurídico. Uma vez reconhecida a importância da fraternidade e seu valor legal, poderá se perceber a contradição da mesma com a existência do adicional de insalubridade, ocasionando em um 
falso cuidado às condições do empregado e ocorrendo também o desrespeito de outros direitos básicos dos trabalhadores como a proteção à saúde e a garantia de um meio-ambiente laboral digno, saudável e decente.

Por fim, serão apresentadas algumas possíveis alternativas ao adicional de insalubridade, tendo como exemplos políticas de saúde e segurança existentes em outros países, onde o foco é minorar os riscos e prevenir o aparecimento de problemas de saúde nos trabalhadores, em vez de indenizar por meio de um pequeno acréscimo financeiro os empregados que arriscam sua integridade física e mental em condições insalubres.

\section{O Adicional de Insalubridade}

O adicional de insalubridade é um dos direitos dos trabalhadores urbanos e rurais que se encontra presente na Constituição Federal de 1988, estando em seu artigo $7^{\circ}$, no inciso XXIII, onde se garante: "adicional de remuneração para as atividades penosas, insalubres ou perigosas, na forma da lei”.

A referida lei é a Consolidação das Leis do Trabalho, onde em sua seção XIII (Das Atividades Insalubres e Perigosas) define o que são atividades insalubres e regulam as situações em que os trabalhadores possuem o direito e os valores pagos de acordo com o grau de insalubridade existente na atividade. Além disso, há a Norma Regulamentador $\mathrm{n}^{\circ} 15$, da Portaria $n^{\circ}$ 3.214/1978 do Ministério do Trabalho, onde são definidos os diferentes tipos de ambientes insalubres existentes.

De acordo com a CLT, as atividades insalubres são:

Art.189 - Serão consideradas atividades ou operações insalubres aquelas que, por sua natureza, condições ou métodos de trabalho, exponham os empregados a agentes nocivos à saúde, acima dos limites de tolerância fixados em razão da natureza e da intensidade do agente e do tempo de exposição aos seus efeitos. (Redação dada pela Lei $\mathrm{n}^{\circ}$ 6.514, de 22.12.1977)

A própria CLT não cita quais são as profissões em que deve ser pago o adicional, tendo essa função sido delegada ao Ministério do Trabalho, por meio de sua Secretaria de Medicina e Segurança do Trabalho, que publica Normas Regulamentadoras e Portarias. Atualmente as condições trabalhistas consideradas insalubres estão classificadas na Norma Regulamentadora $n^{\circ} 15$, da Portaria ${ }^{\circ} 3.214 / 1978$ e em seus anexos.

O adicional de insalubridade é considerado um direito indisponível (não podendo assim o trabalhador renunciar a ele), sendo uma obrigação do empregador pagar aos seus funcionários, e integra o salário, mesmo tendo função indenizatória. Além disso, de acordo com Amauri Mascaro Nascimento, "Cabe à Superintendência Regional do Ministério do 
Trabalho e Emprego exercer a fiscalização e notificar as empresas quanto às operações insalubres, conforme o quadro do Ministério do Trabalho" (NASCIMENTO, 2014, p. 638).

\section{1. Os Tipos de Atividades Insalubres}

Entre as atividades insalubres reconhecidas pelo Ministério do Trabalho estão as que envolvem condições hiperbáricas, agentes químicos (como chumbo, arsênico e mercúrio) e biológicos (como lixo e carnes de animais portadores de doenças infectocontagiosas). Já outras condições só são reconhecidas como insalubres desde que acima do "limite de tolerância", que são as que envolvem exposição ao calor, radiações ionizantes, poeiras minerais, certos agentes químicos, ruído contínuo e ruídos de impacto. Caso não se ultrapasse esse limite de tolerância, o trabalhador não terá direito a nenhum adicional.

De acordo com a Norma Regulamentadora $\mathrm{n}^{\circ}$ 15, limite de tolerância é “...a concentração ou intensidade máxima ou mínima, relacionada com a natureza e o tempo de exposição ao agente, que não causará dano à saúde do trabalhador, durante a sua vida laboral."

Por último existem as atividades insalubres que necessitam a comprovação de um laudo de inspeção do ambiente de trabalho, que são as que expõem os trabalhadores ao frio, à vibrações, à radiações não-ionizantes e à umidade.

O entendimento da jurisprudência do Tribunal Superior do Trabalho é que a lista de atividades insalubres é taxativa, ou seja, mesmo que seja reconhecida a insalubridade de um local de trabalho por meio de perícia, caso a atividade não esteja enquadrada pela Norma Regulamentadora $\mathrm{n}^{\circ} 15$, o empregado não terá o direito ao adicional.

Assim sendo, confirmando essa visão, foram emitidas as Súmulas 448 do TST e 460 do Supremo Tribunal Federal:

Súmula 448: ATIVIDADE INSALUBRE. CARACTERIZAÇÃO. PREVISÃO NA NORMA REGULAMENTADORA No 15 DA PORTARIA DO MINISTÉRIO DO TRABALHO No $3.214 / 78$. INSTALAÇÕES SANITÁRIAS.

I - Não basta a constatação da insalubridade por meio de laudo pericial para que o empregado tenha direito ao respectivo adicional, sendo necessária a classificação da atividade insalubre na relação oficial elaborada pelo Ministério do Trabalho.

Súmula 460 - Perícia Judicial em Reclamação Trabalhista - Enquadramento da Atividade

Para efeito do adicional de insalubridade, a perícia judicial, em reclamação trabalhista, não dispensa o enquadramento da atividade entre as insalubres, que é ato da competência do Ministro do Trabalho e Previdência Social.

\section{2. Os Graus de Insalubridade e seus Respectivos Valores}


Tanto a CLT como a Norma Regulamentadora $n^{\circ} 15$ reconhecem a existência de 3 graus de insalubridade, sendo eles: mínimo, médio e máximo. Cada grau de insalubridade garante um valor de adicional, logo quando maior a insalubridade do ambiente de trabalho, maior o adicional pago ao empregado.

O adicional será de $10 \%$ sobre o salário-mínimo regional para as atividades classificadas como de insalubridade de grau mínimo, de $20 \%$ para o grau médio e de $40 \%$ ao grau máximo. Além do salário-mínimo, a Súmula $\mathrm{n}^{\circ} 17$ do TST permitia o adicional ser calculado sobre o salário profissional quando devido por força de lei, convenção coletiva ou sentença normativa. Entretanto, a súmula foi cancelada.

Caso exista no ambiente de trabalho mais de um tipo de insalubridade, apenas se considera a mais grave no acréscimo salarial, não sendo permitida a acumulação de adicionais de insalubridade. Da mesma forma, a legislação não permite que um trabalhador obtenha o adicional de insalubridade e o de periculosidade ao mesmo tempo, tendo que escolher um deles.

Por fim, caso o empregador consiga eliminar a insalubridade do ambiente de trabalho ou fornecer EPI (Equipamentos de Proteção Individual) que permitam acabar ou reduzir a insalubridade que os empregados se encontram expostos, então o trabalhador perderá o direito ao adicional (caso extinta a insalubridade da atividade) ou poderá ocorrer a mudança de grau de insalubridade e, consequentemente, a alteração do valor do adicional que recebe (caso apenas reduzida a insalubridade). Assim é necessário que o equipamento efetivamente tenha efeito em reduzir/eliminar a nocividade do trabalho, caso contrário o empregador continuará tendo a obrigação de pagar o adicional. (Súmula nº 289 do TST).

\section{O Conceito de Fraternidade na Constituição}

O termo fraternidade surgiu como um ideal político na Revolução Francesa, sendo um dos lemas do movimento junto com igualdade e liberdade. Entretanto, enquanto "liberdade" e "igualdade" se tornaram importantes valores jurídicos e políticos, a fraternidade por muito tempo foi ignorada e vista como de menor importância, não sendo compatível com o direito, demorando mais de um século para a ideia da fraternidade começar a ressurgir e começar a ser vista no mesmo patamar que os outros dois valores iluministas. (SILVA, 2008)

Atualmente tal conceito está abarcado em muitas constituições, entre elas a Constituição Portuguesa de 1976 e Brasileira de 1988, tornando-se em mais do que apenas um conceito filosófico ou um ideal social, como foi no período iluminista francês, mas sim em um princípio jurídico. (MACHADO, 2008) 
A ideia de uma sociedade fraterna está presente no preâmbulo da Constituição de 1988, como um dos objetivos do Estado Brasileiro:

\begin{abstract}
Nós, representantes do povo brasileiro, reunidos em Assembléia Nacional Constituinte para instituir um Estado Democrático, destinado a assegurar o exercício dos direitos sociais e individuais, a liberdade, a segurança, o bem-estar, o desenvolvimento, a igualdade e a justiça como valores supremos de uma sociedade fraterna, pluralista e sem preconceitos, fundada na harmonia social e comprometida, na ordem interna e internacional, com a solução pacífica das controvérsias, promulgamos, sob a proteção de Deus, a seguinte CONSTITUIÇÃO DA REPÚBLICA FEDERATIVA DO BRASIL. (Constituição Federal de 1988)
\end{abstract}

Da mesma forma, em seu inciso I, do art. $3^{\circ}$, é reconhecido como um objetivo fundamental da república "construir uma sociedade livre, justa e solidária”.

Sendo a sociedade fraterna o resultado de um compilado de valores, mesmo que tal termo esteja contido em uma constituição normativa e imperante em momento nenhum a fraternidade pode ser considerada uma norma, logo não pode ser imposta e sim reciprocamente sentida.

Dessa forma Sonilde K. Lazzarin diz que:

A fraternidade pressupõe que a minha liberdade não se possa realizar sem a liberdade do outro, é considerada um princípio que está na origem de um comportamento relacional e, exatamente por isso, além de ser um princípio ao lado da liberdade e da igualdade, aparece como aquele que é capaz de tornar esses princípios efetivos. (LAZZARIN, 2015, p. 93)

Nessa perspectiva, a fraternidade tem que ser compartilhada pelos membros de uma sociedade visando não só o seu bem próprio, mas o bem do conjunto em questão. Sendo um sentimento de irmandade e igualdade. Essa fraternidade como categoria jurídica não se confunde com a fraternidade religiosa ou filosófica, não sendo também uma fraternidade nacionalista, mas sim universal. De acordo com Carlos Machado: "A ideia de fraternidade que se pretende difundir exprime igualdade de dignidade entre todos os homens, independente de organização em comunidades politicamente institucionalizadas". (MACHADO, 2008, p.2).

O entendimento da fraternidade como um princípio constitucional e um dos objetivos do Estado Brasileiro já foi reconhecido em decisões do Supremo Tribunal Federal, como no voto do ex-ministro Carlos Ayres Britto, no julgamento da ADI 3.128, que questionava a cobrança da contribuição previdenciária dos servidores inativos.

[...] apercebi-me de que a solidariedade, como objetivo fundamental da República Federativa do Brasil, em verdade, é fraternidade [...], a significar apenas que precisamos de uma sociedade que evite as discriminações e promova as chamadas 
ações afirmativas ou políticas públicas afirmativas de integração civil e moral de segmentos historicamente discriminados, como o segmento das mulheres, dos deficientes físicos, dos idosos, dos negros, e assim avante.

Tal princípio, atualmente é usado por juízes para chegar a decisões mais justas para as partes, sendo muito comum no Direito do Trabalho, no qual existe a natural disparidade entre empregados e patrões. Sendo assim, tal princípio dá para as partes um sentimento de se colocar no lugar do outro e esquecer essa dicotomia, chegando então a uma decisão realmente justa e condizendo com os fatos apresentados.

Para Juliana Wülfing e Lilian Casagrande:

(...) para a concretização do princípio da fraternidade é fundamental romper com discursos de abstração. Impõe-se a ação da comunidade como um todo, pelo reconhecimento do outro como ser humano, pois a responsabilidade não pertence somente ao Estado, cabe a todos os indivíduos cumprir com o papel de cidadão, vendo o outro na sua própria imagem, vendo o direito do outro, como se fosse seu. (WÜLFING; CASAGRANDE, 2014, p.17)

Com isso, tona-se claro que tal princípio é acima de tudo um sentimento de irmandade e igualdade sendo condizendo com o desejo da Carta Magna de construir uma sociedade igualitária, justa e fraterna. Logo, é um dever de todos nós sentir que o próximo tem os mesmos direitos que nós, portanto merece ser tratado igualmente e com o mesmo respeito que gostaríamos de ser tratados.

\section{O Conflito entre o Adicional de Insalubridade e o Princípio da Fraternidade}

A fraternidade é um princípio que deve estar presente em todos os aspectos da sociedade, sejam eles sociais, econômicos, jurídicos, políticos, e também no local de trabalho, sendo esse um ambiente historicamente desigual, uma relação entre o hipossuficiente e autossuficiente. Nesse âmbito o direito ao adicional de insalubridade viria para tornar essa relação de submissão menos distante e mais humana, entretanto o que se verifica é o oposto, ocorrendo uma monetização da saúde da parte mais fraca da relação de trabalho.

Conforme a Constituição Federal em seu art. $7^{\circ}$, no inciso XXII (exatamente o anterior ao que trata dos adicionais de insalubridade e periculosidade), é direito dos trabalhadores a "redução dos riscos inerentes ao trabalho, por meio de normas de saúde, higiene e segurança". Com isso, evidencia-se que o Poder Constituinte Originário tinha o desejo de ter em primeiro lugar um ambiente de trabalho hígido e digno, mas em casos de impossibilidade de se chegar a esse patamar seria necessário então o adicional de insalubridade, o que seria condizente com os princípios da Constituição de 1988, no entanto, no ambiente de trabalho a realidade é outra. 
Para Leomar Daroncho:

O direito ao adicional de remuneração para atividades insalubres está posicionado em dispositivo posterior àquele que confere o direito dos trabalhadores a verem melhorada sua condição social por meio de normas que reduzam os riscos inerentes ao trabalho, ambos no art. $7^{\circ}$ da Constituição. Na prática, todavia, transforma-se o encargo do empregador em espécie de obrigação alternativa, podendo optar, conforme lhe seja mais conveniente (em geral o que for mais barato!), por manter o meio ambiente de trabalho hígido ou pagar o adicional de insalubridade. (DARONCHO, 2012, p. 51)

A Constituição tem o enfoque de constituir uma sociedade justa, igualitária e fraterna como destacado no seu preâmbulo, no entanto deixou o trabalhador à margem da escolha mais conveniente para o empregador, sendo então uma atitude que distorce o principio da fraternidade, demostrando que a única finalidade do autossuficiente é o lucro, mesmo que para isso tenha que arriscar a saúde de seus semelhantes, os trabalhadores.

Nessa perspectiva cabe à empresa escolher qual alternativa que será mais vantajosa, optando por melhorar o seu ambiente de trabalho, que é um dever da empresa, ou pagar o adicional de insalubridade descrito no art. $7^{\circ}$, inciso XXIII, que é um direito do trabalhador brasileiro. Tal dever é citado no art. 157 da CLT:
Art. 157 - Cabe às empresas:
I - cumprir e fazer cumprir as normas de segurança e medicina do trabalho;
II - instruir os empregados, através de ordens de serviço, quanto às precauções a tomar no sentido de evitar acidentes do trabalho ou doenças ocupacionais;
III - adotar as medidas que lhes sejam determinadas pelo órgão regional competente;
IV - facilitar o exercício da fiscalização pela autoridade competente.

Com isso destaca-se que entre direitos e deveres as empresas optam por pagar o direito do trabalhador, o qual resulta na monetização da saúde desses, sendo uma pratica em conformidade com a lei, a qual exime a empresa de seu dever de oferecer um ambiente seguro para o trabalhador.

Assim evidencia-se a tendência contemporânea da procura por empregos com maiores adicionais por pessoas de menor renda, fazendo com que o adicional de insalubridade não seja mais uma reparação, mas uma vantagem e quanto maior, melhor.

Isso porque a monetização, de um lado, não reconhece e não estimula devidamente investimento em prevenção, visto que basta remunerar com adicionais as condições de risco; e, de outro lado, preserva a alta procura por atividade perigosas ou insalubres em prol de benefícios econômicos como um salário maior. (CNI, 2016, p. 7) 
Tal atitude faz com que o empenho do Estado em tornar o ambiente de trabalho mais seguro para o trabalhador seja uma mera abstração, pois se para os indivíduos que enfrentam essas condições não é um problema a ser sanado, não há uma reivindicação ativa para que os direitos dos trabalhadores e os deveres das empresas sejam cumpridos.

(...) no Brasil a legislação praticamente parou na terceira fase (exame dos riscos globais do ambiente de trabalho), limitando-se à fixação dos adicionais e problematizando superficialmente se estes deveriam ser divididos em níveis ou pagos de maneira uniforme, em detrimento do grau de exposição ou risco. (CNI, 2016, p. 10)

Logo, é destacada a estagnação normativa do Brasil no âmbito de proteção do trabalhador e de sua dignidade humana, a qual está suscitada em nossa Constituição.

\begin{abstract}
$\mathrm{Na}$ atual conjuntura econômica verifica-se a falta de preocupação com o homem, com a sua dignidade. Importa referir que há um núcleo essencial dos direitos sociais que se encontra diretamente conectado ao princípio da dignidade e que é indispensável para uma vida digna e sobre os quais deve haver a proteção contra o retrocesso. (LAZZARIN, 2015, p. 92)
\end{abstract}

Dessa forma, trazemos à luz tais fatos os quais se tornam corriqueiros em nossa atualidade, o que não ratifica uma sociedade fraterna assim como desejada pelos constituintes de nossa Carta Magna.

Segundo Andréia Aparecida Lopes Cançado:

\begin{abstract}
Os obstáculos para a harmonia da convivência entre o capital e a força de trabalho não são de ordem jurídica, uma vez que, como mencionado alhures, não faltam leis que regulem essa relação. A problemática, ao que parece, depende de atitudes mais profundas, morais, espirituais, fraternas, que se conferem à pessoa humana e de como consideramos e se trata o outro. (CANÇADO, 2009, p. 131)
\end{abstract}

Portanto, destacamos que a Constituição, detalhou analiticamente os direitos dos trabalhadores, tentando oferecer condições condizentes com seus princípios, entretanto, nada disso pode ser feito se os empregadores não se sentirem iguais aos trabalhadores em um sentimento de fraternidade, o qual faria com que esses buscassem não o caminho mais fácil e barato para resolver os problemas do ambiente de trabalho, mas o caminho mais humano e fraternal, um caminho que ofereça realmente condições dignas de trabalho para todos.

Nessa perspectiva, torna-se claro que o princípio da fraternidade no ambiente de trabalho viria para humanizar a relação de trabalho, a qual se tornaria mais igualitária fazendo com que a busca por melhores condições laborais fosse recíproca entre o Estado, trabalhadores e patrões, que juntos fariam valer o princípio fraternal presente na Carta Magna e assim constituir uma sociedade justa, igualitária e fraterna. O oposto da humanização da 
relação do trabalho é a mercantilização da força de trabalho e da saúde dos empregados, que ocorre por meio dos adicionais, conforme aponta Vólia Bonfim Cassar:

\begin{abstract}
Aliás, já é absurda a norma que permite que o empregador compre, por ínfimos valores, a saúde do trabalhador, como o faz a CLT. Saúde não se vende nem se compra. Quando a lei determina que o empregador pague o adicional de insalubridade de 10, 20 ou $40 \%$ sobre o salário mínimo ou, sob outro enfoque, $30 \%$ sobre o salário-base para o trabalho perigoso, monetiza o risco, a saúde, o perigo. (CASSAR, 2018, p. 823)
\end{abstract}

Ademais, existe a visão que tal adicional tem o escopo de incentivar o empregador a buscar melhorias do ambiente laboral, já que tal compensação, em algum momento, se tornaria um problema para o contratante, sendo então a extinção ou diminuição das insalubridades a única saída para cessar o pagamento do adicional de insalubridade, logo, o adicional seria não só uma compensação para o trabalhador, mas também uma espécie de castigo para o empregador por oferecer condições que colocam a saúde do trabalhador em risco. (BRASIL, 1987, p. 96)

A proposta inicial do constituinte originário era de majorar o adicional de insalubridade ao percentual de 50\%. Esse adicional não seria somente um plus salarial, mas sim uma coerção legal ao contratante para que efetuasse melhorias nas condições de trabalho e meio ambiente do trabalho. A ata $\mathrm{n}^{\circ} 86$, de 1 julho de 1987, da subcomissão dos direitos dos trabalhadores e servidores públicos, mostra:

[...] se não apertarmos mais o dono do capital aumentando os índices da questão da insalubridade e da periculosidade, e hoje a insalubridade varia entre 10, 20 e $40 \%$ do salário mínimo e a periculosidade é $30 \%$ sobre o salário real. Esta emenda de $50 \%$, os adicionais de insalubridade e de alto risco de periculosidade, é no sentido de fazer com que o empresário invista mais para evitar as áreas de alto risco e insalubridade com a perspectiva de somente assim, ele sentindo no seu bolso, parta para melhores índices. Nós, trabalhadores, não queremos comprar a saúde, queremos evitar trabalhar em áreas insalubres. (BRASIL, 1987, p. 96)

Ao longo das discussões da Assembleia Nacional Constituinte foi debatida a possibilidade de, em vez de aumentar o valor do adicional de insalubridade, reduzir a exposição do trabalhador ao ambiente insalubre por meio da diminuição da jornada de trabalho e também pela eliminação da própria insalubridade quando fosse possível. (BRASIL, 1987, p. 95). Apesar de tal visão estar mais de acordo com as normas trabalhistas internacionais, o adicional é que foi mantido na Constituição, ao contrário da redução de horas de trabalho em locais insalubres.

Apesar de a tese dominante ser que o adicional é uma forma de coagir o empregador a investir em um ambiente de trabalho saudável, na prática o valor do adicional é ínfimo, se 
tornando para certos empregadores mais vantajoso continuar pagando o adicional do que gastar com equipamentos de segurança ou realizar grandes mudanças no local de trabalho para reduzir a insalubridade. A obrigação de manter um meio ambiente de trabalho saudável acaba se tornando em uma alternativa ao empregador, que pode escolher em vez disso pagar o adicional, sendo que o empregado ao receber o valor do adicional estaria aceitando a condição insalubre e seus efeitos a própria saúde. (DARONCHO, 2012, p. 51)

Como destaca o professor Rodrigo Guilherme Tomaz:

Como a base de cálculo destacada pela CLT para o adicional de insalubridade é o ínfimo salário mínimo, desconsiderando-se o valor do salário base do trabalhador, o valor pago como adicional será pífio, mesmo nos casos de grau máximo de insalubridade, o que representa produtos extremamente nocivos à saúde do trabalhador, o que afeta negativamente toda a coletividade. (TOMAZ, 2015, p. 67)

Além disso, o adicional acaba por gerar um estimulo para os trabalhadores mais pobres e necessitados trabalharem em funções insalubres e danosas a sua saúde com o objetivo de complementarem sua renda com o valor a mais que receberão no salário. Tal efeito negativo do adicional é reconhecido mesmo em decisões de Tribunais Regionais do Trabalho:

O pagamento de adicionais, em realidade, nem deveria existir, pois adotadas as medidas de proteção e prevenção adequadas, os ambientes de trabalho seriam sadios e seguros, "na medida do possível e razoável", conforme a Convenção 155 da OIT. Porém, o fenômeno da monetarização situa todo o sistema numa zona de conforto que estimula, de um lado baixos investimentos para prevenção, pois a opção pelo pagamento dos adicionais é mais barata; e de outro a preferência dos próprios trabalhadores de buscar atividades insalubres e perigosas para obter um ganho salarial mais elevado. É evidente que ambas as situações são nefastas. Daí que a maior oneração do gravame monetário é também uma forma pedagógica de direcionar ao interesse pelo maior investimento em prevenção. (TRT da $4^{\mathrm{a}}$ Região, 2a. Turma, 0000259-24.2011.5.04.0761 RO/REENEC, em 19/04/2012, Juiz Convocado Raul Zoratto Sanvicente - Relator. Participaram do julgamento: Desembargadora Tânia Maciel de Souza, Desembargador Alexandre Corrêa da Cruz)

Outro ponto preocupante é a possibilidade que surgiu na Reforma Trabalhista de 2017 (Lei 13.467/17), que no artigo 611-A permite que por meio de um acordo coletivo ou uma convenção coletiva possa ser (inciso XII) alterado o enquadramento do grau de insalubridade e (inciso XIII) também prorrogada a jornada de trabalho em ambientes insalubres, sem precisar de qualquer licença prévia das autoridades competentes. Nesses casos, o que tiver sido negociado terá prevalência sobre a própria lei, mesmo quando não trouxer benefícios aos empregados. A possibilidade de maior tempo de trabalho em uma atividade insalubre, aumentando os riscos que os empregados estarão sujeitos, mostra a pouca preocupação do legislador com os trabalhadores. 
A Reforma Trabalhista também permitiu, por meio do artigo 394-A, que a gestante possa trabalhar em local de insalubridade média ou mínima, e no caso da lactante em qualquer grau de insalubridade, só podendo exigir sua retirada da atividade se apresentar um atestado de um médico de confiança que aconselhe o afastamento. Assim essa foi mais uma matéria onde a questão da saúde e os direitos trabalhistas foram depreciados.

Logo, o adicional de insalubridade existindo como uma forma de livrar o Estado e os empregadores da responsabilidade de protegerem a saúde dos empregados e garantirem um ambiente hígido acaba conflitando com o direito constitucional à saúde, presente no art. $6^{\circ}$ da Constituição Federal como um direito social e repetido no art. 196 com maiores detalhes, assim como o inciso VIII, do art. 200, que define como uma das atribuições do sistema único de saúde: “colaborar na proteção do meio ambiente, nele compreendido o do trabalho."

Vale citar que o Brasil ratificou convenções da Organização Internacional do Trabalho que também tratam sobre a questão da saúde dos trabalhadores, como a Convenção $\mathrm{n}^{\circ} 148$ (Proteção dos Trabalhadores contra os Riscos Profissionais devidos à Contaminação do Ar, ao Ruído e às Vibrações no Local de Trabalho) e a Convenção n 155 (Segurança e Saúde dos Trabalhadores e o Meio Ambiente de Trabalho), tendo elas enfoque na prevenção e na garantia de condições dignas de trabalho. Logo tanto a Constituição, quanto as leis trabalhistas e os tratados internacionais que o Brasil se comprometeu a seguir impõe ao Estado o dever de proteger os trabalhadores. Ao tratar a saúde do homem como um bem possível de se comprar, se desrespeita completamente a dignidade humana e se vai contra qualquer ideia possível de fraternidade.

\section{Alternativas ao Adicional}

A atual legislação brasileira em relação à insalubridade no trabalho vai contra a tendência internacional que em vez de monetizar os riscos à saúde, procura focar na prevenção e em medidas para reduzir ao máximo possível as condições insalubres.

No Canadá, por exemplo, a legislação trabalhista afirma que as ameaças à integridade dos trabalhadores devem ser eliminadas em sua origem, sendo dever dos empregadores de fiscalizar o local de trabalho anualmente, fornecer os equipamentos necessários para proteção dos funcionários e sendo responsável pela proteção aos riscos existentes na atividade. Por outro lado, é obrigação dos empregados seguir os procedimentos em relação à segurança e saúde. (CNI, 2016, p. 35).

Uma visão bastante semelhante possui a legislação espanhola, onde além do empregador ter o dever de cuidar que as condições do ambiente de trabalho sejam saudáveis, 
detectando qualquer perigo ou risco nas atividades exercidas pelos empregados, e fornecer os equipamentos de proteção quando forem necessários, também tem o dever de assegurar vigilância médica periódica aos seus empregados que se encontram expostos a riscos no trabalho. (CNI, 2016, p. 37).

Da mesma forma, vários outros países já adotam há anos políticas trabalhistas de caráter preventivo, entre eles: Holanda, Portugal, Itália, México, Austrália e África do Sul. Esses países possuem leis condizentes com as convenções da OIT que tratam sobre o tema da saúde e segurança no trabalho, como as convenções $\mathrm{n}^{\circ} 148, \mathrm{n}^{\circ} 155$ e $\mathrm{n}^{\circ} 161$, onde os países que assinaram as convenções se comprometem a adotar políticas para prevenir danos e acidentes.

As legislações de tais países são exemplos ao Brasil de políticas alternativas ao adicional de insalubridade. Embora cada país apresente suas próprias características, e por isso é necessário uma legislação adequada à realidade brasileira, as práticas estrangeiras podem servir de exemplo para os legisladores e juristas de como é possível apostar na prevenção e proteção à saúde dos trabalhadores, em vez de insistir na monetização da saúde dos trabalhadores.

Fazer com que os empregadores cumpram o seu dever de garantir um ambiente seguro e saudável para os trabalhadores por meio do fornecimento de materiais de segurança adequados ou a melhoria do ambiente de trabalho, além de obrigar o trabalhador a seguir as normas de segurança impostas, parece ser a melhor alternativa ao adicional.

Outra medida seria diminuir a jornada de trabalho em locais em que não é possível a extinção da insalubridade, o que reduziria a exposição dos trabalhadores aos riscos desses ambientes. Qualquer que sejam as medidas adotadas pelo Brasil, o exemplo internacional mostra que existem alternativas mais protetivas à integridade da saúde dos trabalhadores do que o pagamento do adicional de insalubridade, que sequer é uma medida protetiva na realidade.

\section{Conclusão}

Após a análise do funcionamento do adicional de insalubridade de acordo com a legislação brasileira e as medidas tomadas por outros países com políticas trabalhistas mais preocupadas com a saúde e segurança dos trabalhadores, se percebe que o adicional não é um direito realmente benéfico e protetivo aos empregados, mas sim uma forma legalizada de explorar a saúde dos trabalhadores, indo contra a ideia de fraternidade e a dignidade da pessoa humana. 
Para que seja alcançada a sociedade justa e solidária que garanta a dignidade de todos, conforme idealizado na Constituição como o principal objetivo do Estado, é necessário que o valor da fraternidade esteja presente em todas as relações sociais, inclusive nas relações trabalhistas, não podendo existir uma sociedade justa enquanto ocorrer a exploração da saúde dos trabalhadores, principalmente os de camadas econômicas mais pobres e carentes.

É dever do Estado zelar pela saúde e segurança dos trabalhadores, garantindo que os direitos a um meio ambiente de trabalho seguro e condições dignas de trabalho sejam respeitados. Para tanto é necessário fiscalizar os locais de trabalho, garantindo que os funcionários sempre tenham equipamentos de segurança para reduzir ao máximo possível os danos à saúde, e acabar com a cultura de "compra da saúde" por parte dos empregadores, substituindo por uma política de prevenção e minoração dos riscos.

Com um reconhecimento maior no futuro por parte dos juristas e dos legisladores da importância do princípio da fraternidade na elaboração, interpretação e aplicação do direito, as questões trabalhistas poderão ser resolvidas de forma mais justa e protetiva à dignidade dos trabalhadores, se reconhecendo a importância da prevenção e eliminação dos riscos, em vez da compra da saúde.

\section{Referências}

BRASIL. Constituição (1988). Constituição da República Federativa do Brasil. Brasília, DF: Senado Federal. Disponível em: <http://www.planalto.gov.br/ccivil_03/constituicao/constituicaocompilado.htm>. Acesso em: 20 dez. 2018

BRASIL, Confederação Nacional da Indústria (CNI). Insalubridade E Periculosidade No Brasil: A Monetização Do Risco Do Trabalho Em Sentido Oposto À Tendência Internacional. Brasília, $2016 . \quad$ Disponível em: $<$ http://conexaotrabalho.portaldaindustria.com.br/publicacoes/detalhe/seguranca-e-saude-dotrabalho/adicionais-de-insalubridade-e-periculosidade/189-insalubridade-e-periculosidade-nobrasil-a-monetizacao-do-risco-do-trabalho-em-sentido-oposto-a-tendencia-internacional/> . Acesso em: 20 dez. 2018.

BRASIL. Diário da Assembleia Nacional Constituinte. n. 86. Brasília, DF, 1987. Disponível em: <http://imagem.camara.gov.br/Imagem/d/pdf/sup86anc01jul1987.pdf\#page=96> Acesso em: 21 dez. 2018.

BRASIL. Decreto $n^{\circ}$ 93.413, de 15 de Outubro de 1986. Promulga a Convenção número 148, da Organização Internacional do Trabalho. Diário Oficial [da] República Federativa do Brasil, Brasília, DF. Disponível em: <http://www.planalto.gov.br/ccivil_03/decreto/19801989/D93413.htm> Acesso em: 22 dez. 2018. 
BRASIL. Decreto n ${ }^{1}$ 1.254, de 29 de Setembro De 1994. Promulga a Convenção número 155, da Organização Internacional do Trabalho. Diário Oficial [da] República Federativa do Brasil, Brasília, DF. Disponível em: <http://www.planalto.gov.br/ccivil_03/decreto/19901994/D1254.htm> Acesso em: 22 dez. 2018.

BRASIL. Decreto-lei no 5.452 , de $1^{\circ}$ de maio de 1943. Aprova a Consolidação das Leis do Trabalho. Diário Oficial [dos] Estados Unidos do Brasil, Rio de Janeiro, DF. Disponível em: < http://www.planalto.gov.br/ccivil_03/Decreto-Lei/Del5452.htm> Acesso em: 20 dez. 2018.

BRASIL. Lei N¹3.467, de 13 de Julho de 2017. Altera a Consolidação das Leis do Trabalho. Diário Oficial [da] República Federativa do Brasil, Brasília, DF. Disponível em: < http://www.normaslegais.com.br/legislacao/Lei-13467-2017.htm> Acesso em: 21 dez. 2018.

BRASIL. Portaria $N^{\circ} 3.214$, de 08 de Junho de 1978. Aprova as Normas Regulamentadoras. Disponível em: <http://www.trtsp.jus.br/geral/tribunal2/ORGAOS/MTE/Portaria/P3214_78.html> Acesso em: 11 jan. 2019.

BRASIL. Tribunal Superior do Trabalho. Súmula $\mathrm{n}^{\circ}$ 289. Insalubridade. Adicional. Fornecimento Do Aparelho De Proteção. Efeito. Res. 121/2003, Diário da Justiça 19, 20 e 21.11.2003

BRASIL. Tribunal Superior do Trabalho. Súmula $\mathrm{n}^{\circ}$ 448. Atividade Insalubre. Caracterização. Previsão Na Norma Regulamentadora N ${ }^{\circ} 15$ Da Portaria Do Ministério Do Trabalho No 3.214/78. Instalações Sanitárias. Res. 194/2014, Diário Eletrônico da Justiça do Trabalho, divulgado em 21, 22 e 23.05.2014.

BRASIL. Supremo Tribunal Federal. Súmula $\mathrm{n}^{\circ}$ 460. Diário da Justiça, publicado em 12.10.1964.

CANÇADO, Andréa Aparecida Lopes. O Contrado De Trabalho Do Século XXI E $O$ Esquecido Princípio Da Fraternidade. Rev. Trib. Reg. Trab. $3^{a}$ Reg., Belo Horizonte, v.49, n.79, p.123-148, jan./jun.2009. Disponível em: <https://www.trt3.jus.br/escola/download/revista/rev_79/andrea_aparecida_lopes_cancado.pd f>. Acesso em: 14 dez. 2018.

CASSAR, V. B. Direito do Trabalho: de acordo com a Reforma Trabalhista e a MP 808/2017. São Paulo: MÉTODO, 2018. 1371 p.

DARONCHO, L. Saúde laboral: o Adicional de Insalubridade e o direito fundamental ao meio ambiente de trabalho hígido. Cadernos Ibero-Americanos de Direito Sanitário, Brasília, v.1, n.1, p. 44-66, jan./jun. 2012. Disponível em: < https://www.cadernos.prodisa.fiocruz.br/index.php/cadernos/article/view/38/83> Acesso em: 16 dez. 2018.

LAZZARIN, S. K. O princípio da fraternidade na Constituição Federal Brasileira de 1988. Direito \& Justiça. v. 41, n. 1, p. 92-99, Porto Alegre: jan.-jun. 2015. Disponível em: $<$ http://revistaseletronicas.pucrs.br/ojs/index.php/fadir/article/view/19975/12670>. Acesso em: 05 dez. 2018. 
MACHADO, C. A. A. A Fraternidade como Categoria Jurídico-Constitucional. Conferência proferida no Congresso Nacional - "Direito e Fraternidade", promovido pelo Movimento Comunhão e Direito, no Auditório Mariápolis Ginetta, Vargem Grande Paulista/São Paulo. 26 de janeiro de 2008 .

NASCIMENTO, A. M. Curso de Direito do Trabalho. São Paulo: Saraiva, 2014. 1170 p.

ROMAR, C. T. M. Direito do Trabalho: Esquematizado. São Paulo: Saraiva, 2018. 1058 p.

SILVA, I. R. V. Estudos preliminares sobre a fraternidade no direito. Revista Eletrônica Direito e Política, Programa de Pós-Graduação Stricto Sensu em Ciência Jurídica da UNIVALI, Itajaí, v.3, n.3, $3^{\circ}$ quadrimestre de 2008. Disponível em: <https://siaiap32.univali.br/seer/index.php/rdp/article/view/6151> Acesso em: 10 dez. 2018

SUPREMO TRIBUNAL FEDERAL. ADI 3218 DF. Relatora Ministra Ellen

Gracie. Data de Julgamento: 18/08/2004, Tribunal Pleno, Data de Publicação: Diário da Justiça 18-02-2005 PP-00004 EMENT VOL-02180-03 PP-00450 RDDT n. 135, 2006, p. 216218.

TOMAZ, R. G. A saúde do trabalhador como direito humano fundamental ao meio ambiente artificial do trabalho equilibrado: o estrabismo do adicional de insalubridade. Revista Espaço Acadêmico. v. 15, n. 170, p. 58-68, jul.2015.

WÜLFING, J; CASAGRANDE, L. P. Trabalho E Fraternidade: Um Constitucionalismo Fraternal Para O Direito Do Trabalho. V Encontro da Rede Universitária para o Estudo da Fraternidade (RUEF). Disponível em: $<$ http://www.catedrachiaralubich.org/uploads/artigos/artigos_2014-0708_ruef2012artigoliliancasagrande_pdf_72cc8678dbdb59b557f0c9eda42a060b.pdf $>$. Acesso em: 10 dez. 2018. 